\title{
Priorities in the allocation of scarce resources
}

\author{
K M Boyd and B T Potter Institute of Medical Ethics and General Practitioner, Edinburgh respectively
}

\section{Authors' abstract}

The authors report and comment on student reactions to a clinical example of moral choice in the microallocation of scarce resources. Four patients require dialysis simultaneously, but only one kidney machine is available. What moral, as opposed to clinial, criteria are available to determine who should have priority?

The allocation of scarce resources in health care raises ethical as well as economic questions. These questions can arise in relation both to macroallocation (decisions about which services to provide to which groups) and microallocation (choices about which individuals should benefit from the resources available). In this paper, in order to focus some ethical questions related to microallocation, we report and comment on issues which we have discussed with medical and nursing students in ethics seminars. In these seminars, we have found it useful to introduce the subject by beginning from a hypothetical clinical example.

The example is set in a renal unit which has only one kidney machine available but four patients urgently needing renal dialysis. The students are normally asked which of the four should get priority and why. The information we give them about the patients is this.

1. The first patient is a 36-year-old married lady with two daughters. She has had a long history of urinary tract infections. Her renal function has gradually deteriorated and for some weeks she has been feeling generally unwell with lethargy and depression. Worsening clinical indications make it necessary for her now to go on to dialysis.

2 . The second patient is a 55-year-old professional man who has had chronic renal failure for several years. An earlier renal transplant has failed. He thus has to have long-term dialysis which he manages himself with a machine at home, otherwise living a normal life. Unfortunately, one of the main units of his home dialysis machine has broken and a replacement can be

\section{Key words}

Resource allocation; medical ethics teaching; renal dialysis. obtained only from a manufacturer at a considerable distance: in fact it will take two days to arrive - longer than the patient can afford to wait.

3. The third patient is a 58-year-old, alcoholic, unemployed workman who is grossly obese. He has had renal failure for some time and has multiple problems with his vascular access, the hospital staff suspecting that he may be interfering with it. He often has talked openly about his thoughts of suicide and the staff fear that he may tamper further with his vascular access, with fatal results. He is separated from his wife and has two children whom he never sees.

4. The fourth patient is a 24 -year-old student who has been out camping and has eaten some toadstools which o she mistook for edible mushrooms. This has produced. acute renal failure and she is seriously ill with rapid worsening clinical signs. She urgently requires dialysis. Because of her rapid presentation, her prognosis is expected to be good.

Assuming that all of these patients, in order to survive, require immediate dialysis, which should have priority? In trying to answer this question our students normally consider first whether there are any specifically medical criteria which can help in their choice. This first step follows the established medical procedure known as triage, and is morally defensible on the grounds that resources should not be used if there is no hope of their being employed successfully. The procedure of triage is typically employed on a battlefield or in major disasters when the number of casualties is far greater than the medical personnel can hope to treat. In such contexts priority is given to 1) seriously wounded casualties who need treatment in $\tilde{N}$ order to survive, over 2) less seriously wounded $N$ casualties who are likely to survive without treatment and 3) more seriously wounded casualties who are unlikely to survive even with treatment. The only major departure from this principle is in the case of some members of the second group (less seriously wounded) whom treatment can restore to immediate social usefulness: the normal example here is that of casualties who are themselves doctors or nurses and, if $\mathbb{D}$ treated, thus can help to increase the overall number of $\frac{\Omega}{\Phi}$ lives saved; on battlefields, priority may also be given $\Omega$ to combatants in the same category, whom treatment 
can return to the possible achievement of victory. (The history and ethics of triage are ably and exhaustively discussed by $\mathrm{G} R$ Winslow in his book Triage and Fustice (1).)

Do the medical criteria of triage help to determine which of the four patients requiring dialysis should have priority? An immediate response of many medical and nursing students, often intuitively applying the basic triage principle, is to give priority to the student in acute renal failure, with the mother or the professional man coming next and the workman last. The obvious reasons for giving priority to the student are that she seems the most likely to be restored to normal healthy functioning and that, when this is achieved, the scarce-treatment resource will be free for use elsewhere. In an extreme triage situation this choice might seem justifiable. On the other hand, in an extreme triage situation such as a nuclear attack on a city, for example, anyone requiring hospital or at all complicated treatment might justifiably be excluded from the category of treatable casualties. In triage situations, that is, many 'ordinary means' of prolonging life (to use a traditional distinction) become 'extraordinary'.

In the situation we are considering, however, it reasonably might be argued that dialysis was an ordinary means, at least insofar as normally it would have been offered to all four patients on a routine basis. None of them were likely to survive without it, but with it, all were likely to survive. In terms of the normal practice of the hypothetical renal unit whose problem we ask our students to think about, the basic triage principle thus does not seem to help, since all four patients fall into the first, high-priority category.

Much the same conclusion emerges if we employ two criteria which Professor Bryan Jennett, in his 1983 Rock Carling Lecture, suggests as appropriate to hightechnology medicine generally. The deployment of such medical means, Professor Jennett argues, may be deemed inappropriate if they are likely to prove 'unsuccessful: because the patient has a condition too advanced to respond to treatment', or unsafe : because the complications outweigh the probable benefit' (2). But on the very limited medical information we have mentioned concerning the patients, neither of these criteria would seem to apply to them. They would not even apply to the unemployed workman. His alcoholism and obesity, of course, may reduce his life expectancy, but they do not eliminate it. His remarks about and even gestures towards suicide, moreover, may be evidence of attention-seeking rather than selfdestroying intentions.

At this point in the exercise however, our medical and nursing students are often unwilling to write off medical triage so easily. The problem, they politely suggest, is that the exercise is too artificial, and that there is simply not enough medical information available for any reasonable priority choice to be made. In a real renal unit there would be more clinical material, and clinical differences, to bite on. This protest, we think, has some justification. It is possible, after all, that more detailed clinical investigation of these patients might discover fresh medical information which could consign any one of them to the category of those unlikely to survive even with treatment. In the trial of the late Dr Leonard Arthur, it may be remembered, a crucial turning point was when the defence's paediatric pathologist identified signs, missed by the prosecution's pathologist (who although 'distinguished', was 'not an expert in this field of tiny babies'), that the infant was not, as the prosecution had claimed 'healthy apart from mongolism' (3), and hence that the prosecution had overrated his chances of survival. One does not need to agree with all that Dr Arthur did (about which there are other arguments), to concede, in the general context of treatment priorities, that such clinical details may be the crucial factor in determining when it is no longer appropriate to institute or continue treatment directed to the prolongation of life.

In desiring further medical information before making moral judgements then, our students are making a reasonable point. As Karl Rahner wisely observes, in his discussion of genetic manipulation,

'It is at least possible that the very "detail" of which the theologian is ignorant, or of which he has only a vague notion, might be the decisive factor in his case; it might be the very detail which would alter the whole conclusion' (4).

In microallocation priority decisions then, there clearly are crucial questions which clinical judgement alone can and must answer, with as much certainty as the circumstances allow.

For the sake of the argument however, let us assume that no clinical details have been discovered which remove any of the four patients from the triage category of those who will survive with but not without treatment. But is survival in all their cases desirable? A further criterion suggested by Professor Jennett is that deployment of high-technology medicine may be inappropriate if it is likely to be 'unkind: because the quality of life after rescue is not good enough (or long enough) to have justified the intervention'. An 'obvious example' of this, he writes, would be 'survival after cardiac arrest or severe head injury, that leaves a badly brain-damaged patient' (5). For the present purpose however, this example perhaps proves too much: it implies a clinical judgement much more specific, and much less likely to be contested on specifically clinical grounds, than any which can be made about the four patients, at least on the information available. In relation to the unkindness criterion, of course, this is not to say that clinical judgement can ever prove everything: 'quality-of-life' decisions always involve some moral judgements judgements, that is, which are based on principles contestable in the public forum of reasoned argument. In the case of the four patients, however, not only on 
the information available, but perhaps also in real life, clinical judgement has a much less certain, specific or poor prognosis to offer than in Professor Jennett's example. In relative terms, of course, the student in acute renal failure, if treated, has a very good prognosis; while that of the professional man and the mother may involve remaining (unless transplant were to be successful) on dialysis for the rest of their lives; and this is a prospect which some patients find too much, which is why the suicidal gestures of the unemployed workman cannot be taken lightly. But in none of these cases, we suspect, is the clinical prognosis so poor that, other things being equal, clinical judgement would suggest that the likely quality of life does not justify dialysis. Prior to the present emergency, after all, it had already been judged appropriate on clinical grounds for the professional man and the unemployed workman; and there is nothing in the information available about the mother or the student which suggests that, again on clinical grounds, it is any less appropriate in their cases.

If dialysis is to be judged as inappropriate on quality-of-life grounds then, presumably it must be for moral rather than clinical reasons. A moral argument relevant here might be that ordinary means of prolonging life become extraordinary and inappropriate if they are likely to impose undue burdens on the patient or his/her family. A less technical version of this argument is sometimes advanced by our medical and nursing students when they suggest that low priority might be given to the unemployed workman with suicidal thoughts, on the ground that life itself, or at least life on dialysis, has become a burden to him. The difficulty about this however is not only what has already been said about the possible ambiguity of the man's suicidal gestures, but also that he has not specifically requested that his lifesaving treatment be discontinued. And again, as other students sometimes observe, the person to whom the question of burdens might be more applicable, at least in terms of burdens to her family, is the mother. The relevant judgement here, of course, they point out, would depend on the age of her children and on who else was able and willing to look after them or her. In the irritating absence of such necessary social information however, it is impossible to make any priority judgement about the four patients on qualityof-life grounds.

Let us suppose for a moment however, that all of the students' questions about the circumstances of the four patients could be answered by a doctor with personal knowledge of each of them; and let us also suppose that this doctor believed that there were differences in the likely quality of their respective lives sufficiently significant to put the patients in some order of priority. Would making a judgement of this kind be morally defensible in principle - morally defensible, that is, apart from any consideration of the reasons for this particular order of priority? The problem here, presumably, would be the old argument about how far any utilitarian or felicific calculus is possible - the problem not only of whether anyone ever really knows enough about other people's present and future circumstances, but also of whether anyone is ever able to interpret other people's true wishes with sufficient accuracy. In a moral judgement of such moment as the one we are considering therefore, it might well be argued that the only defensible order of priority would be one in which the patients themselves each had an equal voice. But the problem with this solution is that at least one of the patients - the seriously ill student is probably only half-conscious and thus unconsultable, that a second - the mother - is suffering from depression and thus perhaps unreliable concerning her true wishes, and that a third - the workman - may be in a similar state. Only the professional man may be in his right mind. But would the doctor be justified in disclosing the full facts of the unit's dilemma to him - in effect asking the professional man to justify why he thinks that he should have priority over the other three?

Were the professional man to be asked this, there might seem good intuitive grounds, or at least strong emotional pressures, for him to stand down in favour of the 24-year-old student or the 36-year-old mother. 'Women and children first!' this gentleman, who at least has had his 55 years, might say. Or again he might not. On the grounds of the qualification of the triage principle mentioned earlier - that of social usefulness he might consider that he still had more to contribute. to society than the others. The problem about the social-usefulness qualification of triage however, is that it really is not applicable outside the very narrow circumstances of battlefield or disaster triage. It is not possible, in other words, to determine with any certainty whose contribution to society is likely to be the more valuable, any more than it is possible to say whose past contribution merits giving them priority. Such considerations, on mature reflection, might make the professional man (were he reasonably in love with life and not of Captain Oates's stock) respectfully decline to tell the doctor what he thought, while perhaps privately thinking that such decisions were what doctors were paid to take. The unemployed workman, on the other hand, were he in one of his more suicidal moods, might interpret the doctor's asking him what he thought as the Black Spot, society's final rejection of him as likely to contribute little and as deserving less.

These speculations suggest then that a doctor might have good reasons for not sharing the full facts of the dilemma with his patients. Such hard decisions, when they are unavoidable, he might agree, are those he is paid to take. It might not be impossible, of course, that the unemployed workman would rise to the occasion, and find a kind of meaning and dignity in standing down voluntarily, so that 'nothing in his life became him like the leaving it'. But before giving this opportunity to a vulnerable patient, most doctors would think long and hard about the damage it might 
do not only to the patient, and the doctor's own relationship with him, but also to doctor-patient relationships in general.

In this context a further criterion proposed by Professor Jennett may be noted. Deployment of hightechnology medicine may be inappropriate if it is 'unwise: because it diverts resources from activities that would yield greater benefits'. Taking the discussion of priorities beyond our consideration of a choice between four known patients, Professor Jennett explains that this criterion 'involves the choice between expenditure on this patient now as against other unknown patients' (5). This criterion seeks, as we understand it, to provide some corrective to the medical preference for 'identified lives' over 'statistical lives' (6) which are nevertheless no less real lives. In the clinical context, presumably, the criterion of unwisdom would be used in conjunction with Professor Jennett's 'unsuccessful', 'unsafe', or even 'unkind' criteria. But much the same criterion has been used by Dr Christoph Benn (6) for example, to illustrate how, at the macroallocation level, concentrating on crisis-intervention services may present resources being allocated to the prevention (in more people, because prevention is cheaper) of the same crisis-creating conditions. Similarly, but broadening the focus to include biomedical research funding, Professor James Gustafson argues that, given scarce resources, 'research that leads to prevention of severe diseases has priority over that which dramatically and at high cost is targeted to end-stages of disease' (7). The point is well-taken. On the other hand, as Dr Benn notes, 'statistical lives should never replace identified lives, because that would result in a sterile system, where care is replaced by counting economical figures and charity by management' (8). Consequently, he writes, doctors 'should continue to provide help for individual patients and in that sense it is right to separate administration and care' (9).

In microallocation priority decisions of the kind we examine with our students then, Professor Jennett's criterion of the 'unwise' is one used by those who, in macroallocation, determine the resource limits which result in the kind of dilemma faced by the hypothetical renal unit. Within this context, the criterion seems appropriate to microallocation choices only if used in conjunction with others. To use it on its own would be to deny to someone like the unemployed workman the confirmation of his value by the doctor, who may be the only person in this situation able and willing to defend this. Moreoever, as Professor James Childress has observed.

'Society may have a stake in protecting the patientphysician relationship and the delivery of health care from the economic language of investment and return. It may value the relationship of "personal care" even when it is not productive. If the physician looks through the patient to society and tries to realize society's goals, the relationship of personal care and trust would be radically altered' (10).
At the end of the ethics seminars, our medical and nursing students often feel that most votes still go to the student, and least to the workman, with the other two patients either second or third in order of priority. At the same time however, they normally agree that this choice cannot be defended on rational moral grounds. A final criterion proposed by Professor Jennett is that the deployment of high-technology medicine may be inappropriate if it is 'unnecessary: because the desired objective can be achieved by simpler means'. In the case of the four patients also, the need to choose proved unnecessary (for the example is based on a real incident), and again because simpler means were available. Although only one machine was available for dialysis, it was possible to keep two patients (the mother and the workman); alive by intermittent peritoneal dialysis, an uncomfortable procedure (since the time of the case replaced by a more comfortable one) involving the insertion of a large needle into the abdomen. The student was put on the machine until she recovered and the RAF recruited to fly in the replacement unit for the professional man's home dialysis machine. The problem of denying 'ordinary means' of life-preseving treatment thus was avoided. A significant point to emerge from this, however, is that dialysis is only an 'ordinary means' once patients have been referred for treatment by their general practitioners. For hospital doctors therefore, as one hard-pressed British consultant recently told some researchers from the Brookings Institution, the⿳亠二口犬 important thing 'is not to get eyeball to eyeball with' a? treatable patient when there are no resources with which to treat him, 'because if you do, there is no way that you can actually say no' (11).

Kenneth Boyd is the Scottish Director of the Institute of Medical Ethics and Brian Potter is a General Practitioner in Edinburgh.

\section{References}

(1) Winslow G R. Triage and justice. London: University of California Press, 1982.

(2) Jennett B. High technology medicine. London: Nuffield Provincial Hospitals Trust, 1984: 133.

(3) Brahams D, Brahams M. The Arthur case - a proposal for legislation. Fournal of medical ethics 1983; 9: 12.

(4) Rahner K. Theological investigations: 9. London Darton, Longman and Todd 1972: $225 \mathrm{seq}$

(5) See reference 2: 134.

(6) Benn C. Resource allocation, preventive health care and the significance of community, unpublished MA dissertation, University of Leeds, 1985: 19.

(7) Gustafson J M. Ethics from a theocentric perspective Vol 2. London: University of Chicago Press 1984: 276.

(8) See reference (6): 22.

(9) See reference (6): 23.

(10) Childress J. Priorities in the allocation of health care resources. In: Smith D H, Bernstein L M, eds. No rush to judgement. Bloomington Indiana: Poynter Center, 1978: 285.

(11) Aaron H J, Schwartz W B. The painful prescription. Washington DC: The Brookings Institution, 1984: 107. 